\title{
Effects of residual doses of neonicotinoid (imidacloprid) on metabolic rate of queen honey bees Apis mellifera (Hymenoptera: Apidae)
}

\author{
Jonathan Vergara-AMAdo ${ }^{1}$, Catalina MAnzI ${ }^{1}$, Lida Marcela Franco ${ }^{2}$, \\ Sebastian C. Contecha ${ }^{2}$, Silvia Juliana Marquez ${ }^{2}$, Jaiber J. Solano-Iguaran ${ }^{1}$, \\ Ronie E. HARO ${ }^{1}$, Andrea X. SILVA ${ }^{1}$ \\ ${ }^{1}$ Instituto de Ciencias Ambientales y Evolutivas, Facultad de Ciencias, Universidad Austral de Chile, Valdivia, Chile \\ ${ }^{2}$ Facultad de Ciencias Naturales y Matemáticas, Universidad de Ibagué, Carrera 22, Calle 67, Ibagué, Colombia
}

Received 18 November 2019 - Revised 18 May 2020 - Accepted 30 June 2020

\begin{abstract}
Bees are key regulators in the maintenance of global biodiversity and food security. Overwhelming evidence has shown elevated colony losses for honey bees and a decrease in the abundance of other pollinators. Insecticides of the neonicotinoid type have been associated with these losses, but few studies have explored how residual exposure doses affect the queen's energy metabolism. Here, we studied how a residual dose of neonicotinoid (imidacloprid), combined with reproductive status (virgin and inseminated) affects honey bee queen's metabolism. We conducted the same experiment in two geographical locations (Chile and Colombia) and found a strong reduction of standard metabolic rate (SMR) in insecticide-treated queens (Chilean queen bees $11.3 \%$ reduction in watt output; Colombian queen bees $11.7 \%$ reduction in watt output). No effects were found when comparing reproductive condition on SMR. We will highlight the possible consequences of a weak honey bee queen's performance on colony stability.
\end{abstract}

\section{honey bee races / insecticide / Chile / Colombia / respirometry}

\section{INTRODUCTION}

Global change, perhaps the most notorious consequence of human activity on Earth, has many facets: habitat losses due to extension of crops fields (Keys and McConnell 2005), loss of genetic diversity (Pauls et al. 2013), invasion of alien species (Vitousek et al. 2017), pathogen propagation (Ayres and Lombardero 2000) and pollination crisis due to the massive use of agrochemicals and, particularly, insecticides (Potts et al. 2010; Sánchez-Bayo and Wyckhuys

Corresponding author: A. Silva, andrea.silva@uach.cl

Manuscript editor: Marina Meixner
2019). Today, insecticides are used on several crop types, provoking systemic damage at several levels. This, in turn, permits rapid reduction of pest populations, theoretically without persisting in the agroecosystem (Devine and Furlong 2007; Vanbergen and the Insect Pollinators Initiative 2013). This is especially important for beneficial insects such as pollinators, which can be seriously affected.

Imidacloprid (IMD) is a type of neonicotinoid insecticide and one of the most commonly applied worldwide, representing $41.5 \%$ of the global market, followed by thiamethoxam and clothianidin (Jeschke et al. 2010). These insecticides target the insect's central nervous system, acting as agonists of the postsynaptic nicotinic acetylcholine receptor (nAChRs) (Blacquiere et al. 2012; Brown et al. 
2006), which results in an initial depolarization and ultimately suppresses synaptic transmission in the postsynaptic membrane (Buckingham et al. 1997). Insecticides enter the arthropods' body either by direct consumption of contaminated food (nectar and pollen) (Dively and Kamel 2012) and plant exudates (e.g. guttation drops) (Girolami et al. 2009) or by contact through exposure to contaminated air during sowing (Girolami et al. 2012; Marzaro et al. 2011).

Studying residual insecticide doses at the level of the agroecosystem is challenging, as they are practically undetectable by most instruments but usually induce subtle changes in the honey bee's physiology. Few studies have addressed the effect of neonicotinoids sublethal exposure on honey bee's metabolic physiology, including energy homeostasis, which is an important aspect for maintaining colony health (Cook 2019). In addition, there are currently no studies about the effect of residual insecticide doses on the queen's physiology. The metabolic physiology of organisms is an indicator of performance capacity in important aspects of behavioural development by honey bees, such as foraging capacity, feeding brood, hive maintenance and queen care. These effects could reflect the colony health and have consequences on honey bee colony losses ( $\mathrm{Li}$ et al. 2017).

Numerous studies focused on A. mellifera have demonstrated that low doses of neonicotinoid do not result in mortality. They do, however, cause sublethal effects leading to beehives weakening (Godfray et al. 2015; Woodcock et al. 2017). Sublethal and residual IMD doses affect the overwintering success (Blacquiere et al. 2012), reproduction ability (Chaimanee et al. 2016), colony genetic diversity (Forfert et al. 2017), immune system (Brandt et al. 2016; Derecka et al. 2013) and susceptibility to diseases (Alaux et al. 2010; Aufauvre et al. 2014) of bees. Sublethal and residual IMD doses also cause alterations to behaviours such as learning and orientation (Aliouane et al. 2009; Fischer et al. 2014) and patterns of foraging activity (Schneider et al. 2012; Yang et al. 2008). Communication efficiency (Tison et al. 2016), flying performance
(Desneux et al. 2007; Kirchner 1999) and gene expression are also altered (Derecka et al. 2013; Koo et al. 2015; Siede et al. 2012).

Most of the evidence discussed above has been obtained exclusively for worker caste bees, but it is known that queen failure is a major driver of managed honey bee colony losses. Little data exist, however, concerning effects of environmental stressors on queens (Williams et al. 2015). An appropriate experiment addressing the effects of residual insecticide doses on honey bees should study the final impact on queens. Here, we studied how residual doses of imidacloprid (2.5 part per billion, ppb) combine with the reproductive status (hereafter insemination factor, IF: virgin and inseminated) to have an impact on the metabolic rate of queens. We chose aerobic metabolism (i.e. standard metabolic rate, measured as $\mathrm{CO}_{2}$ production) as a proxy of physiological performance, as this single variable represents the intensity of functioning at a given moment (Kovac et al. 2007).

We conducted the same experiment in two geographical locations, Chile and Colombia, using the local honey bee races. In Chile, we used the Western honey bee (WHB) derived from Apis mellifera carnica and in Colombia a honey bee race with any grade of Africanization (a hybrid between of the Western and the African honey bee Apis mellifera scutellata), called the Africanized honey bee (AHB). We expect a similar SMR reduction result in both bee races.

\section{MATERIALS AND METHODS}

\subsection{Insects}

We performed the same experiments in two geographical locations with contrasting climate conditions: a temperate location (Chile) and a tropical location (Colombia). We used 30 healthy queens derived from Apis mellifera carnica (Western honey bee, WHB) and another 31 derived from Apis mellifera scutellata (Africanized honey bee, AHB). Both were provided from a commercial supply in Chile and Colombia, respective to each study conducted. For each location, the supplier artificially inseminated half of the queens through the standard method (Cobey et al. 2013), and the other half remained virgin. 
Before insemination, each newly virgin queen was in an individual nucleus colony for several days (5-14). After this, each queen was supplied with 20 attendant worker bees from their established nucleus colony for about 7 to 12 days that provide it with food, which we in turn supplied as a prepared formula (see below). Each queen and her workers were maintained in individual wooden cages $(20 \times 12 \times 9 \mathrm{~cm})$.

\subsection{Experimental setup and maintenance}

The wooden cages were put in a climatic chamber at $30 \pm 1{ }^{\circ} \mathrm{C}$ and continuous darkness. Food was periodically supplied ad libitum in $2: 1: 1$ organic honey/sugar (100\% sucrose)/water syrup, pollen cake ( $80 \%$ pollen and $20 \%$ syrup) and water. These initial conditions were established and maintained for 4 days before the initiation of the experiment.

\subsection{Insecticide treatment}

A stock solution at 20 ppm of imidacloprid (IMD) (Sigma-Aldrich; dissolved in $\mathrm{H}_{2} \mathrm{O}$ and stored light-protected at $4{ }^{\circ} \mathrm{C}$ ) was dissolved daily in the experimental syrup to attain the desired concentration of $2.5 \mathrm{ppb}$. The dose was selected based on the mean concentrations usually found in field-realistic conditions (Carreck and Ratnieks 2014). Hence, we contrasted two experimental conditions with different insecticide exposures (IE), control (feeding without IMD) and treatment (feeding containing $2.5 \mathrm{ppb}$ IMD), in an orthogonal design with the insemination difference for reproductive status (insemination factor, IF: virgin and inseminated queens).

\subsection{Metabolic rate measurements}

The metabolic rate of each queen bee was measured once after the 4 days of exposure to treatments. All individuals were weighed on analytical balance (Radwag, Poland) before and after each measurement. We recorded carbon dioxide production $\left(\mathrm{VCO}_{2}\right)$ as a proxy for standard metabolic rate (SMR) in a respirometry system similar to what is described in Lighton and Turner (2004). This uses an infrared $\mathrm{CO}_{2}$ analyser (Li-COR Inc.,
Lincoln, NE, USA LI6251) capable of reaching differences of 1 ppm of $\mathrm{CO}_{2}$ in air. In this system, the air input was dried and filtered of $\mathrm{CO}_{2}$ using a column with soda lime on the ambient air input. The airflow was maintained by a mass flow controller (Sierra Instruments, Monterey, CA, USA) at $300 \mathrm{~mL} / \mathrm{min}$, and the line was connected to a $2 \mathrm{~mL}$ measuring chamber (Sable System, Las Vegas, NV, USA) in line to the $\mathrm{VCO}_{2}$ analyser. Activity was simultaneously recorded by an AD-1 linear activity unit (Sable System), which has an infrared detector for movement with a photovoltaic cell sensor. The activity report of bees allowed us to ensure that metabolic measures were used when queens were in resting periods. Each queen was measured for a total of $40 \mathrm{~min}$ at the same temperature as during thermal acclimation $\left(30 \pm 1{ }^{\circ} \mathrm{C}\right)$.

\subsection{Data record}

We used the ExpeData software (Sable Systems), where each record was corrected for the time lag between the start points of both input signals. We also discarded the first $10 \mathrm{~min}$ to avoid manipulative stress records. All queens exhibited discontinuous gas-exchange cycles (DGC); thus, we took an average $\mathrm{VCO}_{2}$ of three complete DGC cycles. Hence, the final average of released $\mathrm{VCO}_{2}$ in $\mathrm{ppm}$ per unit of time was transformed to $\mathrm{mL}$ of $\mathrm{CO}_{2} \mathrm{~h}^{-1}$, and finally, taking into account the flow rate and respiratory quotients (RQ), it was transformed to watt units $(\mathrm{J} / \mathrm{s})$ following the conversion method proposed by Walsberg and Wolf (1995). The thermal equivalent of carbon dioxide production varies with metabolic substrates, and the RQ value used must be in accordance with the experimental diets (i.e. carbohydrates, $\mathrm{RQ}=1.0$; lipid, $\mathrm{RQ}=0.71$; protein, $R Q=0.74)$. We use an $R Q=1$ that assumes that the proportion of $\mathrm{CO}_{2}$ produced is equal to the $\mathrm{O}_{2}$ consumed. Finally, we estimated the change in metabolic rate as the percent reduction in $\mathrm{VCO}_{2}$ of queens exposed to IMD treatment in relation to the control.

\section{6. . Statistical analyses}

We tested the combined effects of insecticide exposure (IE) and insemination factor (IF) on 
SMR by a factorial design where IE had two levels (control and insecticide) and IF had also two levels (virgin and inseminated queens). Thus, to evaluate the effect of our predictive variables on SMR (in watts), we used a factorial ANCOVA including body mass $(\mathrm{Mb})$ as a covariate. For all cases, we performed a logarithmic transformation of metabolic rate and $\mathrm{Mb}$ values. Parametric assumptions were verified using the Levene and Wilcoxon tests (Levene 1960; Wilcoxon 1992). All analyses were performed using the $\mathrm{R}$ studio software (R project) (Team 2014). We tested each experiment's location (Chile and Colombia) in separate models, given that we study different subspecies, and the intergroup comparison is not the aim.

\section{RESULTS}

No queen died in any of the treatments during the acclimation period (4 days) or during the metabolic rate measurements (4 days). We found that both experiments of the Western honey bees (WHB) from Chile and Africanized honey bees (AHB) from Colombia had similar qualitative results. That is, we found a significant reduction of standard metabolic rate (SMR) as a consequence of insecticide exposure (WHB $F_{(1,27)}=$ $5.65, p=0.025$; AHB $\left.F_{(1,28)}=10.47 ; p=0.003\right)$ (Table 1). In contrast, we found no effects of the insemination factor (virgin and inseminated queen) on SMR (WHB $F_{(1,27)}=0.008, p=$ 0.928 ; AHB $\left.F_{(1,28)}=0.013 ; p=0.911\right)$. The metabolic depression of insecticide-treated Chilean queens (WHB) was $11.3 \%$ in relation to the control diet $(x \pm$ SE: $0.0027 \pm 0.0007 \mathrm{~W}$ in control versus $0.0013 \pm 0.0002 \mathrm{~W}$ in treatment; Figure 1a.), and for Colombian queens (AHB), the reduction in SMR was $11.7 \%(x \pm \mathrm{SE}$ : $0.0059 \pm 0.009 \mathrm{~W}$ in control versus $0.032 \pm$ $0.004 \mathrm{~W}$ in treatment; Figure 1b.).

\section{DISCUSSION}

Most studies targeting neonicotinoid effects of residual doses often use Apis mellifera worker caste, giving less emphasis to other castes, such as queens and drones. In addition, little is known about the imidacloprid (IMD) effects on the bee standard metabolic rates (SMR), and only few studies have reported that insect exposure to low IMD concentrations may alter respiratory rates (Cook 2019; Hatjina et al. 2013; Zafeiridou and Theophilidis 2004). Here, we explore the effect of IMD residual doses on SMR $\left(\mathrm{CO}_{2}\right.$ production) of virgin and inseminated Apis mellifera queens. Two different Apis mellifera races (Western honey bee, WHB; and Africanized honey bee, AHB) of queen bees were exposed at 4 days to residual IMD doses administered in their diets under

Table 1. ANOVA results for each honey bee races study.

\begin{tabular}{lllll}
\hline & df & Sum sp. & F & P-value \\
\hline Apis mellifera carnica (WHB; Chile) & & & & \\
Body mass & 1 & 0.010 & 0.108 & 0.745 \\
Insecticide Exposure (IE) & 1 & 0.050 & 5.652 & $\mathbf{0 . 0 2 5}$ \\
Insemination factor (IF) & 1 & 0.001 & 0.008 & 0.928 \\
IE x IF & 1 & 0.205 & 2.316 & 0.141 \\
Apis mellifera africanized (AHB; Colombia) & & & \\
Body mass & 1 & 0.021 & 0.448 & 0.509 \\
IE & 1 & 0.484 & 10.473 & $\mathbf{0 . 0 0 3}$ \\
IF & 1 & 0.001 & 0.013 & 0.911 \\
IE x IF & 1 & 0.016 & 0.344 & 0.562 \\
\hline
\end{tabular}

Chilean honey bee queen of Apis mellifera carnica race (Western honey bee; WHB), and Colombian honey bee queen, a hybrid between the Western and the African honey bee Apis mellifera scutellata race, in this study called the Africanized honey bee $(\mathrm{AHB}) . \mathrm{IF}=$ Insemination Factor; IE = Insecticide Exposure. Significant values in bold. 


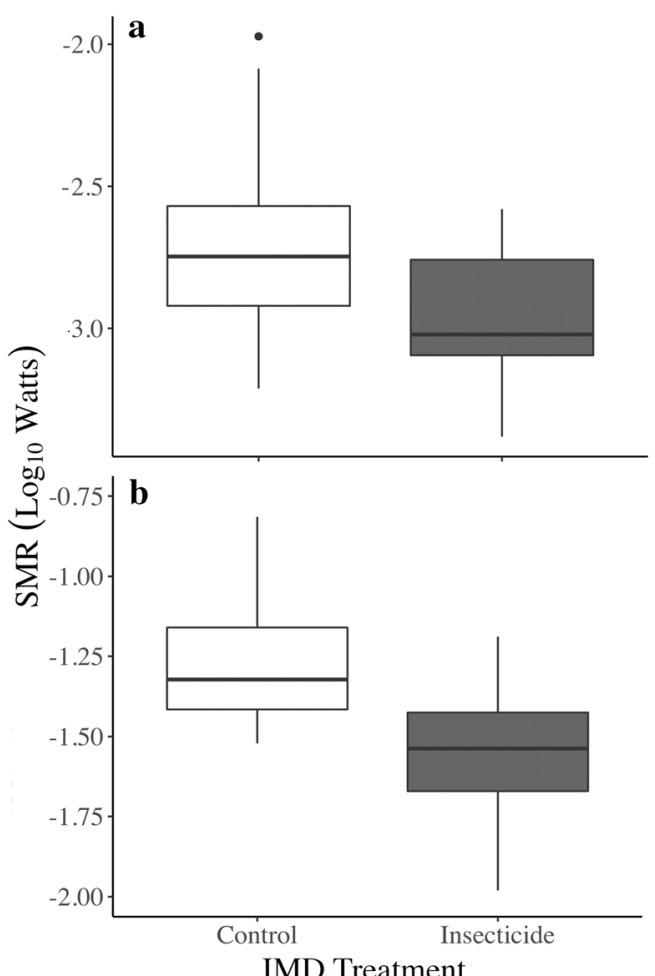

Figure 1. Standard metabolic rate (SMR). Boxplot of standard metabolic rate (SMR) of queen bees from a Chile and $\mathbf{b}$ Colombia. Effect of the insecticide exposure: control (without insecticide) and insecticide imidacloprid (2.5 pbb) treatment on the metabolic rate in $\log _{10}$ Watts of queen bees.

laboratory conditions. No insect mortality was observed during the whole experiment. Typical IMD lethal doses (LD50 oral) for this species range from 3.7 to 183 ppm (Laurino et al. 2010; Schmuck et al. 2001; Suchail et al. 2001), so as was expected, the chosen concentration in this work $(2.5 \mathrm{ppb})$ that is widely detected in natural environments (Carreck and Ratnieks 2014; Mullin et al. 2010) did not cause mortality. Our study shows that residual IMD doses significantly disrupt the queen honey bee's respiration, which was observed as the depression of SMR in both studied races. Similar results have been previously reported in workers bees. Hatjina et al. (2013) found that the intervals between each abdominal ventilation movements (AVM) increased and burst frequencies decreased in worker bees exposed to residual IMD doses, suggesting a suppressive effect on $\mathrm{CO}_{2}$ and $\mathrm{O}_{2}$ gas exchange and metabolic activity (Contreras and Bradley 2010). Studies monitoring the respiratory rhythm of the Tenebrio molitor beetle showed that $50 \mathrm{ng}$ of IMD per insect caused a respiratory contraction reduction of $40 \%$ (Zafeiridou and Theophilidis 2006). A recent study of metabolic physiology on honey bee workers found a decrease in respiration rates $\left(\mathrm{CO}_{2}\right.$ production) when using IMD doses of $50 \mathrm{ppb}$, but not with a residual dose of 5 ppb (Cook 2019). Our experiment detected similar respiration decrease effect, but using a half residual dose (2.5 ppb), most likely due to higher queen sensitivity than other bee caste. For instance, colony exposure to residual neonicotinoid doses has been associated with increasing queen supersedure, but not with colony survival (Sandrock et al. 2014).

Residual IMD doses cause decrease of the hypopharyngeal gland (HPG) size in worker bees (Hatjina et al. 2013). Attendant worker bees produce royal jelly, which they use to feed queen bees to allow for their development and proper functioning (Crailsheim 1992). A decrease in HPGs will directly affect the quality and/or amount of royal jelly produced by attendant workers and could have consequences on queen's health and metabolism, given that this nutrient is the main diet of this bee caste.

For organisms that are able to occupy stressful environments, reductions in metabolic rates are thought to be important adaptations (Chown and Gaston 1999), and these reductions have been implicated in adaptations to elevated temperature (Hoffmann and Parsons 1989), food and water stress (Gibbs et al. 1997) and elevated $\mathrm{CO}_{2}$ exposure (Donahaye 1992). Because metabolism implies an ATP cost (Sibly and Calow 1989), the advantage of decreasing metabolic rate under resource-limited conditions or stressful environments could be to conserve ATP such that it is only used for primary needs (Chown and Gaston 1999). Thus, given that IMD lower dose exposure has been associated with increases in thermoregulation expenses (Crall et al. 2018; Potts et al. 2018) and a decrease in ATP synthesis (Powner et al. 2016), the reduction in queen bee's metabolism could be related to a redirection of energy expenditure against the stressful effect of IMD. To 
give a concrete example of the direct and indirect implication of the reduction in the queen bee's metabolic rate, consider the secretion of pheromones. The queen's pheromone secretion would be reduced upon IMD dosing, since its production and release implies an energy cost. Changes in pheromone secretion alter the queen's oviposition rate and the behaviour of the worker bees, triggering an imbalance in the hive (Holman 2012).

All inseminated queen bees used in this work were artificially inseminated, eliminating the energetic cost for the nuptial flight and probably explaining why the reproductive state did not affect the metabolism or interact with IMD exposures. It is known that queens are able to store sperm of different drones in a specialized organ called the spermatheca, keeping male gametes in optimal conditions. This organ releases sperm gradually during the queen's life to fertilize the eggs. During our experiments, there was no oviposition by the queens, and thus, energy expenditure associated to fecundity was eliminated as a factor.

Therefore, this study pioneers documenting the consistent reduction of metabolism under residual doses of IMD in A. mellifera queens. In addition, the reduction was observed for both of the studied honey bee races, from temperate and tropical locations, indicating that the observed response could be environmental independent among races (WHB and AHB). A series of physiological, behavioural and reproductive alterations may be partly a consequence of this reduction.

\section{CONCLUSION}

While numerous studies have focused on behavioural effects of imidacloprid (IMD) on honey bees, few studies have focused on physiological effects of this insecticide, specifically in castes other than workers (i.e. drones and queens). Our study shows that under laboratory conditions, IMD generates a depression of SMR in A. mellifera queen bees, pointing out the need for more research on physiological effects, given the negative consequences on bee queens and their indirect effect on hive development. Our study uncovers a wide range of effects triggered by extremely low doses of a common insecticide used in agriculture.

\section{AUTHORS' CONTRIBUTIONS}

JVA and CM performed analysis and wrote the paper; LMF and AXS participated in the design and interpretation of the data; SCC, SJM and REH performed experiments; JJSI performed statistical analyses.

\section{FUNDING INFORMATION}

This study was funded by FONDECYT Grant No. 11140680 to A.X. Silva and Project N ${ }^{\circ} 16-427-$ INT to L.M. Franco from the Dirección de Investigaciones de la Universidad de Ibagué; Colombia. We thank Roberto Nespolo for kindly assessing us with the $\mathrm{CO} 2$ flow-through respirometry methods and the LiCor 6251 we used at his lab (funded by Fondecyt grant 1180917).

Effets des doses résiduelles de néonicotinoïde (Imidaclopride) sur le taux métabolique des reines abeilles Apis mellifera (Hymenoptera:apidae).

races d'abeilles / insecticides / Chili / Colombie / respirométrie.

Effekte von Rückstandsdosen eines Neoniktotinoids (Imidacloprid) auf die Stoffwechselrate von Honigbienenköniginnen Apis mellifera (Hymenoptera:Apidae).

Honigbienenrassen / Insektizide / Chile / Kolumbien / Respirometrie.

\section{REFERENCES}

Alaux C., J.L. Brunet, C. Dussaubat, F. Mondet, S. Tchamitchan, et al. (2010) Interactions between Nosema microspores and a neonicotinoid weaken honeybees (Apis mellifera). Environmental microbiology 12 (3): 774-782.

Aliouane Y., A.K. El Hassani, V. Gary, C. Armengaud, M. Lambin, et al. (2009) Subchronic exposure of honeybees to sublethal doses of pesticides: effects on behavior. Environmental Toxicology and Chemistry: An International Journal 28(1): 113-122. 
Aufauvre J., B. Misme-Aucouturier, B. Viguès, C. Texier, F. Delbac, et al. (2014) Transcriptome analyses of the honeybee response to Nosema ceranae and insecticides. PLoS One 9(3): e91686.

Ayres M.P., M.J. Lombardero. (2000) Assessing the consequences of global change for forest disturbance from herbivores and pathogens. Science of the Total Environment 262 (3): 263-286.

Blacquiere T., G. Smagghe, C.A. Van Gestel, V. Mommaerts. (2012) Neonicotinoids in bees: a review on concentrations, side-effects and risk assessment. Ecotoxicology 21 (4): 973-992.

Brandt A., A. Gorenflo, R. Siede, M. Meixner, R. Büchler. (2016) The neonicotinoids thiacloprid, imidacloprid, and clothianidin affect the immunocompetence of honey bees (Apis mellifera L.). Journal of insect physiology 86 : 40-47.

Brown L.A., M. Ihara, S.D. Buckingham, K. Matsuda, D.B. Sattelle. (2006) Neonicotinoid insecticides display partial and super agonist actions on native insect nicotinic acetylcholine receptors. Journal of neurochemistry 99 (2): 608-615.

Buckingham S., B. Lapied, H. Corronc, F. Sattelle. (1997) Imidacloprid actions on insect neuronal acetylcholine receptors. Journal of experimental biology $\mathbf{2 0 0}(21)$ : 2685-2692.

Carreck N.L., F.L. Ratnieks. (2014) The dose makes the poison: have "field realistic" rates of exposure of bees to neonicotinoid insecticides been overestimated in laboratory studies? Journal of Apicultural Research 53 (5): 607-614.

Chaimanee V., J.D. Evans, Y. Chen, C. Jackson, J.S. Pettis. (2016) Sperm viability and gene expression in honey bee queens (Apis mellifera) following exposure to the neonicotinoid insecticide imidacloprid and the organophosphate acaricide coumaphos. Journal of insect physiology 89 : 1-8.

Chown S.L., K.J. Gaston. (1999) Exploring links between physiology and ecology at macro-scales: the role of respiratory metabolism in insects. Biological Reviews 74 (1): $87-120$

Cobey, S. W., Tarpy, D. R., \& Woyke, J. (2013) Standard methods for instrumental insemination of Apis mellifera queens. Journal of Apicultural Research, 52 (4): 1-18.

Contreras H., T. Bradley. (2010) Transitions in insect respiratory patterns are controlled by changes in metabolic rate. Journal of Insect Physiology 56(5): 522528.

Cook S.C. (2019) Compound and dose-dependent effects of two neonicotinoid pesticides on honey bee (Apis mellifera ) metabolic physiology. Insects $\mathbf{1 0}(1)$ : 18 .

Crailsheim K. (1992) The flow of jelly within a honeybee colony. Journal of comparative physiology B 162 (8): 681-689.

Crall J.D., C.M. Switzer, R.L. Oppenheimer, A.N.F. Versypt, B. Dey, et al. (2018) Neonicotinoid exposure disrupts bumblebee nest behavior, social networks, and thermoregulation. Science 362 (6415): 683-686.
Derecka K., M.J. Blythe, S. Malla, D.P. Genereux, A. Guffanti, et al. (2013) Transient exposure to low levels of insecticide affects metabolic networks of honeybee larvae. PLoS One 8(7): e68191.

Desneux N., A. Decourtye, J.-M. Delpuech. (2007) The sublethal effects of pesticides on beneficial arthropods. Annu. Rev. Entomol. 52 : 81-106.

Devine G.J., M.J. Furlong. (2007) Insecticide use: contexts and ecological consequences. Agriculture and Human values 24 (3): 281-306.

Dively G.P., A. Kamel. (2012) Insecticide residues in pollen and nectar of a cucurbit crop and their potential exposure to pollinators. Journal of agricultural and food chemistry 60 (18): 4449-4456.

Donahaye E. (1992) Physiological differences between strains of Tribolium castaneum selected for resistance to hypoxia and hypercarbia, and the unselected strain. Physiological Entomology 17 (3): 219-229.

Fischer J., T. Mueller, A.-K. Spatz, U. Greggers, B. Gruenewald, et al. (2014) Neonicotinoids interfere with specific components of navigation in honeybees. PloS one 9 (3): e91364.

Forfert N., A. Troxler, G. Retschnig, L. Gauthier, L. Straub, et al. (2017) Neonicotinoid pesticides can reduce honeybee colony genetic diversity. PloS one 12 (10): e0186109.

Gibbs A.G., A.K. Chippindale, M.R. Rose. (1997) Physiological mechanisms of evolved desiccation resistance in Drosophila melanogaster . Journal of Experimental Biology 200 (12): 1821-1832.

Girolami V., L. Mazzon, A. Squartini, N. Mori, M. Marzaro, et al. (2009) Translocation of neonicotinoid insecticides from coated seeds to seedling guttation drops: a novel way of intoxication for bees. Journal of economic entomology 102 (5): 1808-1815.

Girolami V., M. Marzaro, L. Vivan, L. Mazzon, M. Greatti, et al. (2012) Fatal powdering of bees in flight with particulates of neonicotinoids seed coating and humidity implication. Journal of Applied Entomology $136(1-2)$ : 17-26.

Godfray H.C.J., T. Blacquiere, L.M. Field, R.S. Hails, S.G. Potts, et al. (2015) A restatement of recent advances in the natural science evidence base concerning neonicotinoid insecticides and insect pollinators. Proceedings of the Royal Society B: Biological Sciences 282 (1818): 20151821.

Hatjina F., C. Papaefthimiou, L. Charistos, T. Dogaroglu, M. Bouga, et al. (2013) Sublethal doses of imidacloprid decreased size of hypopharyngeal glands and respiratory rhythm of honeybees in vivo. Apidologie 44 (4): 467-480.

Hoffmann A., P. Parsons. (1989) An integrated approach to environmental stress tolerance and life-history variation: desiccation tolerance in Drosophila. Biological Journal of the Linnean Society 37 (1-2): 117-136.

Holman, L. (2012). Costs and constraints conspire to produce honest signaling: insights from an ant queen pheromone. Evolution: International Journal of Organic Evolution, 66 (7): 2094-2105.) 
Jeschke P., R. Nauen, M. Schindler, A. Elbert. (2010) Overview of the status and global strategy for neonicotinoids. Journal of agricultural and food chemistry 59 (7): 2897-2908.

Keys E., W.J. McConnell. (2005) Global change and the intensification of agriculture in the tropics. Global environmental change 15(4): 320-337.

Kirchner W. (1999) Mad-bee-disease? Sublethal effects of imidacloprid (Gaucho) on the behaviour of honeybees. Apidologie (France) 30(5): 421-422

Koo J., T.-G. Son, S.-Y. Kim, K.-Y. Lee. (2015) Differential responses of Apis mellifera heat shock protein genes to heat shock, flower-thinning formulations, and imidacloprid. Journal of Asia-Pacific Entomology 18 (3): 583-589.

Kovac H., A. Stabentheiner, S.K. Hetz, M. Petz, K. Crailsheim. (2007) Respiration of resting honeybees. Journal of insect physiology 53 (12): 1250-1261.

Laurino D., A. Manino, A. Patetta, M. Ansaldi, M. Porporato. (2010) Acute oral toxicity of neonicotinoids on different honey bee strains. Journal of Zoology 93 (01): 99-102

Levene H. (1960) Robust tests for equality of variances.[In:] Contributions to Probability and Statistics: Essays in Honor of Harold Hotelling. Eds. I. Olkin, H. Hotteling, Stanford University Press, Redwood City.

Li Z., M. Li, J. He, X. Zhao, V. Chaimanee, et al. (2017) Differential physiological effects of neonicotinoid insecticides on honey bees: A comparison between Apis mellifera and Apis cerana. Pesticide biochemistry and physiology 140 : 1-8.

Lighton J.R., R.J. Turner. (2004) Thermolimit respirometry: an objective assessment of critical thermal maxima in two sympatric desert harvester ants, Pogonomyrmex rugosus and P. californicus. Journal of Experimental Biology 207 (11): 1903-1913.

Marzaro M., L. Vivan, A. Targa, L. Mazzon, N. Mori, et al. (2011) Lethal aerial powdering of honey bees with neonicotinoids from fragments of maize seed coat. Bulletin of Insectology 64 (1): 119-126.

Mullin C.A., M. Frazier, J.L. Frazier, S. Ashcraft, R. Simonds, et al. (2010) High levels of miticides and agrochemicals in North American apiaries: implications for honey bee health. PloS one 5 (3): e9754.

Pauls S.U., C. Nowak, M. Bálint, M. Pfenninger. (2013) The impact of global climate change on genetic diversity within populations and species. Molecular ecology 22 (4): 925-946.

Potts S.G., J.C. Biesmeijer, C. Kremen, P. Neumann, O. Schweiger, et al. (2010) Global pollinator declines: trends, impacts and drivers. Trends in ecology \& evolution 25 (6): 345-353.

Potts R., R.M. Clarke, S.E. Oldfield, L.K. Wood, N.H. de Ibarra, et al. (2018) The effect of dietary neonicotinoid pesticides on non-flight thermogenesis in worker bumble bees (Bombus terrestris ). Journal of insect physiology 104 : 33-39.

Powner M.B., T.E. Salt, C. Hogg, G. Jeffery. (2016) Improving mitochondrial function protects bumblebees from neonicotinoid pesticides. PloS one $11(11)$ : e0166531.

Sánchez-Bayo F., K.A. Wyckhuys. (2019) Worldwide decline of the entomofauna: A review of its drivers. Biological conservation 232 : 8-27.

Sandrock C., M. Tanadini, L.G. Tanadini, A. Fauser-Misslin, S.G. Potts, et al. (2014) Impact of chronic neonicotinoid exposure on honeybee colony performance and queen supersedure. PLOS one 9(8): e103592.

Schmuck R., R. Schöning, A. Stork, O. Schramel. (2001) Risk posed to honeybees (Apis mellifera L, Hymenoptera) by an imidacloprid seed dressing of sunflowers. Pest Management Science: formerly Pesticide Science 57 (3): 225-238.

Schneider C.W., J. Tautz, B. Grünewald, S. Fuchs. (2012) RFID tracking of sublethal effects of two neonicotinoid insecticides on the foraging behavior of Apis mellifera. PloS one 7 (1): e30023.

Sibly R., P. Calow. (1989) A life-cycle theory of responses to stress. Biological Journal of the Linnean Society 37 (1-2): 101-116.

Siede R., M.D. Meixner, R. Büchler. (2012) Comparison of transcriptional changes of immune genes to experimental challenge in the honey bee (Apis mellifera). Journal of Apicultural Research 51 (4): 320-328.

Suchail S., D. Guez, L.P. Belzunces. (2001) Discrepancy between acute and chronic toxicity induced by imidacloprid and its metabolites in Apis mellifera. Environmental Toxicology and Chemistry: An International Journal 20 (11): 2482-2486.

Team R.C. (2014) A language and environment for statistical computing. Vienna, Austria: R Foundation for Statistical Computing, ISBN 3-900051-07-0. http://www.R-project.org.

Tison L., M.-L. Hahn, S. Holtz, A. Rößner, U. Greggers, et al. (2016) Honey bees' behavior is impaired by chronic exposure to the neonicotinoid thiacloprid in the field. Environmental science \& technology $\mathbf{5 0}$ (13): 7218-7227.

Vanbergen A.J., the Insect Pollinators Initiative. (2013) Threats to an ecosystem service: pressures on pollinators. Frontiers in Ecology and the Environment 11 (5): 251-259.

Vitousek P.M., L.L. Loope, R. Westbrooks. (2017) Biological invasions as global environmental change. American Scientist 84 : 468-478

Walsberg G., B. Wolf. (1995) Variation in the respiratory quotient of birds and implications for indirect calorimetry using measurements of carbon dioxide production. Journal of Experimental Biology 198 (1): 213-219.

Wilcoxon F. (1992) Individual comparisons by ranking methods, Breakthroughs in statistics, Springer, pp. 196-202.

Williams G.R., A. Troxler, G. Retschnig, K. Roth, O. Yañez, et al. (2015) Neonicotinoid pesticides severely affect honey bee queens. Scientific reports $5: 14621$.

Woodcock B., J. Bullock, R. Shore, M. Heard, M. Pereira, et al. (2017) Country-specific effects of neonicotinoid 
pesticides on honey bees and wild bees. Science 356 (6345): 1393-1395.

Yang E., Y. Chuang, Y. Chen, L. Chang. (2008) Abnormal foraging behavior induced by sublethal dosage of imidacloprid in the honey bee (Hymenoptera: Apidae). Journal of economic entomology 101 (6): 1743-1748.

Zafeiridou G., G. Theophilidis. (2004) The action of the insecticide imidacloprid on the respiratory rhythm of an insect: the beetle Tenebrio molitor. Neuroscience letters 365 (3): 205-209.
Zafeiridou G., G. Theophilidis. (2006) A simple method for monitoring the respiratory rhythm in intact insects and assessing the neurotoxicity of insecticides. Pesticide biochemistry and physiology 86 (3): 211-217.

Publisher's note Springer Nature remains neutral with regard to jurisdictional claims in published maps and institutional affiliations. 